\title{
ACCURATE MODELLING AND TRANSIENT MESHING ANALYSIS OF INVOLUTE SPUR GEAR BASED ON THE PRINCIPLE OF GEAR SHAPING
}

\author{
Zeng, Q. L.\#; Wang, K.; Wan, L. R. \& Zhang, X. \\ College of Mechanical and Electronic Engineering, Shandong University of Science and Technology, \\ Qingdao 266590, China \\ E-Mail: qlzeng@ @sdust.edu.cn ( ${ }^{\#}$ Corresponding author)
}

\begin{abstract}
The gear is one of the most widely used and vital parts having freeform surfaces. Accurate modelling and strength calculation are the basis of gear design and optimization. The traditional gear design and the existing finite element analysis methods cannot effectively solve these problems. Only a simple model can be established and the static strength analysis can be carried out at a certain meshing position. In this study, accurate equations of the tooth surfaces of a spur gear were derived based on the principle of gear shaping. Then, the parametric finite element modelling and simulation of the transient meshing of the spur gear have been realized using ANSYS software, and the stress distribution and variation trends of the gear during the meshing process have been analysed. Finally, the method is verified by simulation and comparison. The analysis results show that the effect of the tooth fillet surface on the strength of the gear is very large, and the bending stress and contact stress of the gear are nonlinear in the meshing process. The proposed method can accurately establish the model including the tooth fillet surface of the spur gear, and accurately analyse the strength of the spur gear pair. This makes up for the shortcomings of the existing method, and can be applied to other gear forms after appropriate modification.

(Received, processed and accepted by the Chinese Representative Office.)
\end{abstract}

Key Words: Spur Gear, Gear Shaping, Meshing Equation, Modelling, Transient Analysis

\section{INTRODUCTION}

A gear is an essential part of transmission device, and its service life and reliability have significant influence on the overall performance of the machine. In the process of gear design and optimization, strength calculation is a key element. There are two factors affecting the accuracy of strength calculation. The primary is the accuracy of the strength analysis model. Because of the complexity of the tooth profile surface and root fillet surface, accurate description of the gear structure is regarded as the premise of strength calculation. The second factor is to take into account the non-linear changes of the meshing condition and stress during the meshing process. In the traditional gear design method, the bending strength of the tooth is calculated based on the model of Lewis cantilever beam [1], and the contact strength of the tooth surface is calculated according to Hertz contact theory [2]. In the process of calculation, tooth and fillet surfaces are respectively simplified as uniform beam and cylindrical surface, with many empirical parameters also being used, which leads to a large deviation between the calculated results and the actual values. With the development of computer technology, the finite element method has been applied to the strength calculation of gears as well as other complex parts. However, the existing scholarly literature on finite element analysis still does not solve the two key technical problems of accurate modelling and nonlinear meshing. Strength calculation is the basis of the gear design and optimization, and it is necessary to establish an accurate model of the gear and analyse the distribution and varieties of stress during gear meshing.

Spur gears are widely used in current gear mechanisms, and many scholars have studied their modelling and calculation of strength. Hwang et al. [3] used the finite element method 
(FEM) to calculate the tooth contact stress of the gears compared with the traditional theory. It is proved that the FEM can be well applied to calculate the gear strength, but the principle of gear modelling is not offered. Forte et al. [4] added the photoelastic experiment on the basis of the above method to further analyse the contact stress however, still did not resolve the same problem of gear modelling. Lias et al. [5] studied the gear bending stress of spur gears in misalignment condition by modelling and analysis in software ANSYS, while the root fillet surfaces were replaced by cylindrical surfaces, which caused inevitable errors in the analysis results. Yusuf et al. [6] used the geometrical method based on NURBS surface modelling to directly generate the FE model of a spur gear composed of regular hexahedral elements, avoiding the complicated meshes generation process in ANSYS. Since the root fillet surface of the gear was still replaced by a cylindrical surface, the problem of modelling accuracy was still not solved. Kanber [7] combined the finite element method with the boundary element method to analyse the stress and deformation of the spur gear, but only used a two-dimensional model for analysis. Karpat et al. [8] studied the dynamic characteristics of the asymmetric spur gear, but did not consider the factor of tooth width. To date, two-dimensional equations have mainly been used to describe the tooth profile curves rather than the tooth surface [9]. Shun and Yan [10] created a three-dimensional gear model in Pro/E, and then imported it to ANSYS for dynamic simulation analysis. As the simplified load at the top of the tooth did not match the actual load, the calculation precision could not meet the requirements. Pawar and Utpat [11] studied the tooth root bending stress of the composite spur gear, but did not consider the effect of the dynamic meshing characteristics on the stress. Fetvaci and Imrak [12] used a two-dimensional model of a single tooth based on the principle of machining to analyse the bending stress at different pressure angles of an asymmetric spur gear. Since the gear was simplified as a single tooth model, and the load was applied on the top of the tooth, which was not consistent with the characteristics of the gear meshing, the analysis results were of no practical value. The above studies were restricted by various factors and the vast majority used cylindrical surface approximation as the root fillet surface, which is different from the actual shape of the gear. In addition, most of the calculations for gear strength in these studies correspond to specific meshing positions, ignoring the dynamic characteristics of the load during the meshing process and the nonlinearity of stress changes.

In view of the existing problems in the above studies, this paper deduced tooth surface equations of the spur gear based on the principle of gear shaping. Then the parametric finite element model of the gear pair was created by parametric design language (APDL) of ANSYS, and the transient simulate analysis of gear meshing was performed. The distribution and varieties of the bending stress and contact stress of the gears were obtained. In the process of modelling and analysis, the accuracy of the model and the nonlinearity of gear meshing have been fully considered. Finally, simulation analysis and comparison were conducted to analyse the effect of the different gear models on gear strength analysis.

\section{DOUBLE-DEGREE FREEDOM MESHING THEORY OF GEAR SHAPING}

\subsection{Construction of the coordinate systems for gear shaping}

The principle of gear shaping is similar to the engagement transmission between rack and gear. The cutting surface of the cutter corresponds to the tooth surface of the rack. There is a conjugate relationship [13] between the cutting surface of the rack cutter and the gear tooth surface. 
As shown in Fig. 1, during the cutting process, according to principle of vector decomposition [14], the gear tooth surface $\sum^{(2)}$ rotates around the axis I with clockwise angular velocity $\omega^{(2)}$ while the cutting surface $\Sigma^{(1)}$ translates along axis II with velocity $\mathrm{V}_{02}$ and translates along the direction that is perpendicular to the plane formed by the axes I and II with velocity $\mathrm{V}_{01}$ at the same time. The axes I and II are parallel to each other and the distance is equal to the pitch circle radius $r_{2}$ of the spur gear.

The rack cutter and gear are placed in three coordinate systems of the space. $\sigma=\{O ; \mathrm{i}, \mathrm{j}, \mathrm{k}\}$ is the regular coordinate system, axis k coincides with axis II, axis $\mathrm{j}$ is in the same direction as $\mathrm{O}_{2} \mathrm{O}$, and axis $\mathrm{i}$ is determined by the right-hand rule. $\sigma^{(1)}=\left\{O_{1} ; \mathrm{i}_{1}, \mathrm{j}_{1}, \mathrm{k}_{1}\right\}$ is the cutter coordinate system with which the regular coordinate system coincides. $\sigma^{(2)}=\left\{O_{2} ; \mathrm{i}_{2}, \mathrm{j}_{2}, \mathrm{k}_{2}\right\}$ is the gear coordinate system which rotates around axis $\mathrm{k}_{2}$ with the meshing rotation of gear. In the initial machining position, axis $\mathrm{k}_{2}$ is aligned with axis $\mathrm{I}$, axis $\mathrm{j}_{2}$ is aligned with $\mathrm{O}_{2} \mathrm{O}$ and axis $i_{2}$ is determined by the right-hand rule.

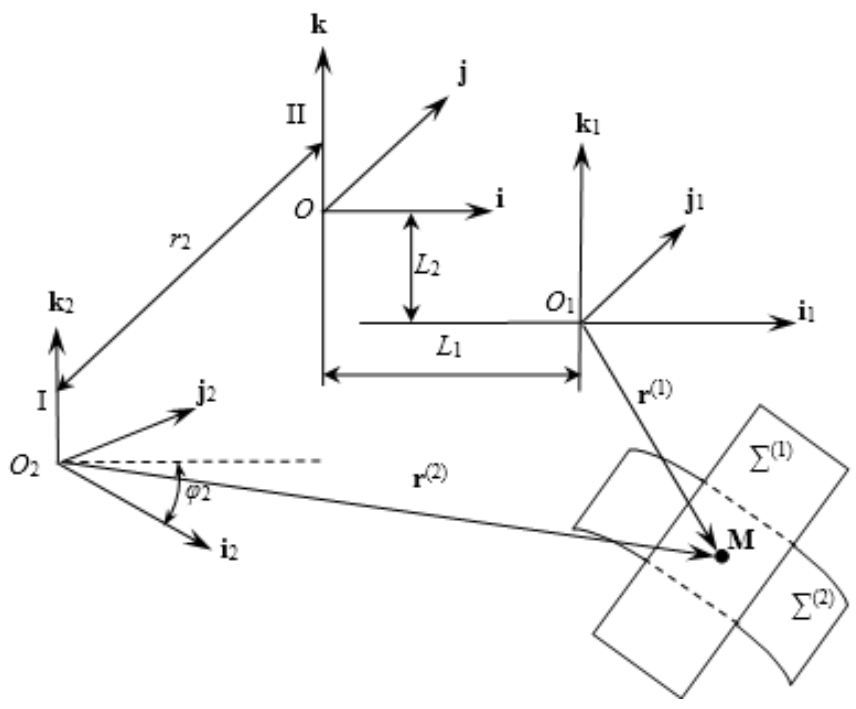

Figure 1: Position and coordinate system of rack cutter and spur gear.

After the time $t$, the cutter moved the distances $L_{1}$ and $-L_{2}$ respectively along the axes $\mathrm{i}$ and $\mathrm{k}$. The gear has rotated the angle $\varphi_{2}$ clockwise respective to the initial position at this moment. Meanwhile, the cutting surface $\sum^{(1)}$ and the gear tooth surface $\sum^{(2)}$ conjugate meshing at point $\mathrm{M}$. As shown in Fig. $1, \mathrm{r}^{(1)}$ is the vector of point $\mathrm{M}$ in $\sigma^{(1)}$ and $\mathrm{r}^{(2)}$ is the vector of point $\mathrm{M}$ in $\sigma^{(2)}$. According to the correlation between the relevant variables, it is easy to determine that $L_{1}=\mathrm{V}_{01} t, L_{2}=\mathrm{V}_{02} t$ and $\varphi_{2}=\omega^{(2)} t$. As $L_{1}=r_{2} \varphi_{2}, \omega^{(2)}$ can be expressed as follows:

$$
\boldsymbol{\omega}^{(2)}=\frac{\mathbf{V}_{01}}{r_{2}}
$$

The angular velocity $\omega^{(2)}$ can be represented by $V_{01}$ as Eq. (1), which means only two independent parameters, $\mathrm{V}_{01}$ and $\mathrm{V}_{02}$, exist in the meshing of rack cutter and spur gear. The contact stress is closely related to the elastic modulus, which changes with the various carbon concentrations for carburized gears. Calculating contact stress using Eq. (1) will cause error and cannot reflect the actual contact stress accurately.

\subsection{Equation of meshing for gear shaping}

In the initial machining position, cutter coordinate system $\sigma^{(1)}$ coincides with the regular coordinate system $\sigma$. Axis $\mathrm{j}_{2}$ coincides with axis $\mathrm{j}$. Let the coordinates of the meshing point $\mathrm{M}$ in $\sigma$ be $(x, y, z)$. The velocity of cutting surface $\mathrm{V}_{1}$ and the velocity of gear tooth surface $\mathrm{V}_{2}$ in the regular coordinate system $\sigma$ are respectively determined by Eqs. (2) and (3): 


$$
\mathbf{V}_{1}=V_{01} \mathbf{i}-V_{02} \mathbf{k}
$$

where $V_{01}=r_{2} \omega_{2}$.

$$
\mathbf{V}_{2}=\boldsymbol{\omega}^{(2)} \times \mathbf{r}^{(2)}
$$

where $\omega^{(2)}=-\omega_{2} \mathrm{k} ; \mathrm{r}^{(2)}=x \mathrm{i}+\left(y+r_{2}\right) \mathrm{j}+z \mathrm{k}$.

The relative velocity $\mathrm{V}^{(12)}$ of meshing point $\mathrm{M}$ is shown as Eq. (4).

$$
\mathbf{V}^{(12)}=-y \omega_{2} \mathbf{i}+x \omega_{2} \mathbf{j}-V_{02} \mathbf{k}
$$

In order to facilitate the subsequent calculation, relative velocity $\mathrm{V}^{(12)}$ is represented by the coordinates of point $\mathrm{M}$ in $\sigma^{(1)}$. Vector $r^{(1)}$ in $\sigma^{(1)}$ is transformed into $\sigma$ as follows:

$$
\mathbf{r}=\mathbf{M}_{01} \mathbf{r}^{(1)}+\mathbf{r}_{01}
$$

where $\mathbf{r}^{(1)}=\left[x_{1} y_{1} z_{1}\right]^{\mathrm{T}}, \mathrm{M}_{01}$ is the coordinate transformation matrix of $\sigma^{(1)}$ to $\sigma, \mathbf{r}_{01}$ is the vector of the origin $O_{1}$ of cutter coordinate system $\sigma^{(1)}$ in regular coordinate system $\sigma$.

The relative velocity $\mathrm{V}^{(12)}$ in coordinate system $\sigma^{(1)}$ can be obtained by taking the result of Eq. (5) into Eq. (4), as expressed in Eq. (6):

$$
\mathbf{V}^{(12)}=-y_{1} \omega_{2} \mathbf{i}_{1}+\left(x_{1}+r_{2} \varphi_{2}\right) \omega_{2} \mathbf{j}_{1}-V_{02} \mathbf{k}_{1}
$$

When the gear is processed by an interpolation cutter, the equation of meshing between the cutting surface and the tooth surface in coordinate system $\sigma^{(1)}$ is shown in Eq. (7):

$$
\mathbf{n}^{(1)} \cdot \mathbf{V}^{(12)}=0
$$

where the unit normal vector $\mathrm{n}^{(1)}$ can be calculated by the following equation:

$$
\mathbf{n}^{(1)}=\frac{\mathbf{r}_{\mu}^{(1)} \times \mathbf{r}_{v}^{(1)}}{\left|\mathbf{r}_{\mu}^{(1)} \times \mathbf{r}_{v}^{(1)}\right|}
$$

where $\mu$ and $v$ are variables of the cutting surface equation, $\mathbf{r}_{\mu}^{(1)}$ is the partial derivative of $\mu$ for the cutting surface equation, $\mathbf{r}_{v}^{(1)}$ is the partial derivative of $v$ for the cutting surface equation.

\section{CUTTING SURFACE EQUATIONS OF RACK CUTTER}

The meshing equation above requires the cutting surface equations of the cutter. The following is a detailed description of the cutting surface for a rack cutter. Fig. 2 shows the tooth shape of the end face of the rack cutter.

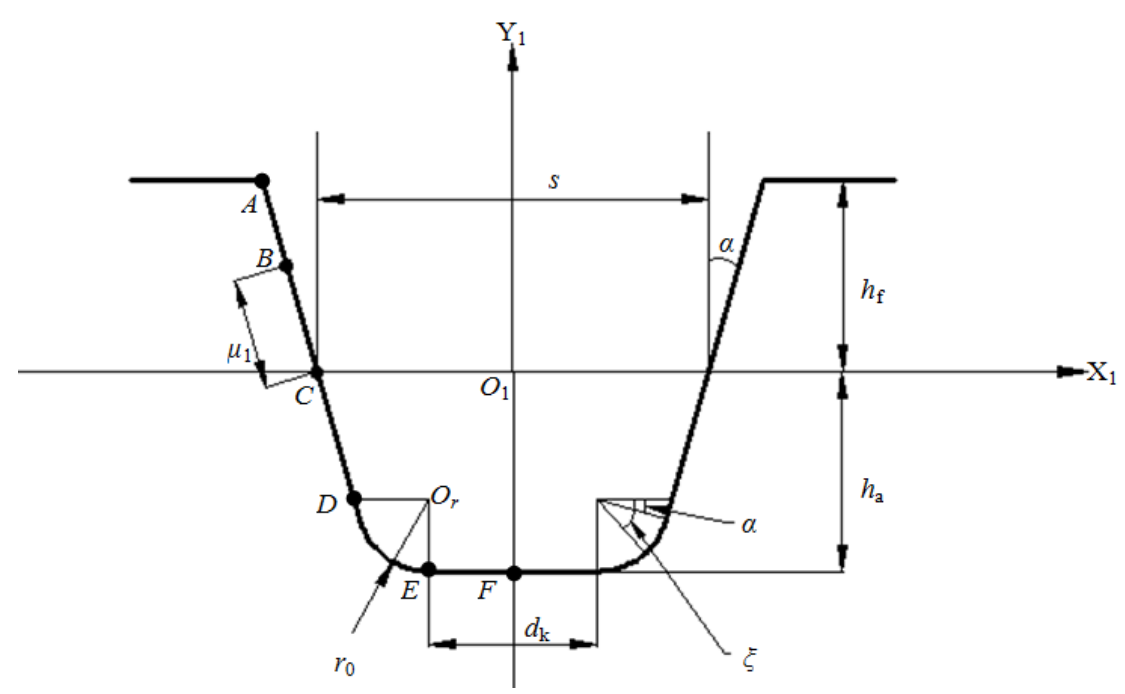

Figure 2: Tooth shape of the rack cutter. 
The relevant parameters in Fig. 2 are as follows: $\alpha$ is the tooth profile angle, $s$ is the tooth thickness at the pitch line, $h_{\mathrm{f}}$ and $h_{\mathrm{a}}$ are respectively the dedendum and addendum, $d_{\mathrm{k}}$ is the addendum width, $r_{0}$ is the corner radius, $\mu_{1}$ is the distance from point $C$ to any point $B$ in line $A D$. If the ordinate of point $B$ is greater than zero, $\mu_{1}$ takes a positive value, otherwise it takes a negative value. $\xi$ is the angle between axis $X_{1}$ and the line that connects any point on the top fillet to the centre point of the top fillet.

The tooth surface equation of each section of the cutter can be obtained by the parameter relationships in Fig. 2.

The equation of section $A D$ can be expressed as follows:

$$
\mathbf{r}^{(1)}\left(\mu_{1}, v\right)=\left(-\frac{s}{2}-\mu_{1} \sin \alpha\right) \mathbf{i}_{1}+\mu_{1} \cos \alpha \mathbf{j}_{1}+v \mathbf{k}_{1}
$$

where $v$ is the variable of width of the cutter tooth, $v \in[0, b], b$ is the width of the rack cutter, $\mu_{1} \in\left(-\mu_{\mathrm{f}}, \mu_{\mathrm{a}}\right)$, and $\mu_{\mathrm{f}}=\frac{h_{\mathrm{f}}}{\cos \alpha}, \mu_{\mathrm{a}}=\frac{h_{\mathrm{a}}-r_{0}+r_{0} \sin \alpha}{\cos \alpha}$.

The equation of section $D E$ can be expressed as follows:

$$
\mathbf{r}^{(1)}(\xi, v)=\left(-\frac{d_{\mathrm{k}}}{2}-r_{0} \cos \xi\right) \mathbf{i}_{1}+\left(-h_{\mathrm{a}}+r_{0}-r_{0} \sin \xi\right) \mathbf{j}_{1}+v \mathbf{k}_{1}
$$

where $d_{k}=s-2 r_{0} \cos \alpha-2\left(h_{a}-r_{0}+r_{0} \sin \alpha\right) \tan \alpha ; \xi \in\left(0, \frac{\pi}{2}\right)$.

The equation of section $E F$ can be expressed as follows:

$$
\mathbf{r}^{(1)}(w, v)=w \mathbf{i}_{1}-h_{\mathrm{a}} \mathbf{j}_{1}+v \mathbf{k}_{1}
$$

where $w \in\left[-\frac{d_{\mathrm{k}}}{2}, 0\right]$.

Since the tooth profile of the rack cutter is symmetrical with respect to the axis $\mathrm{Y}_{1}$, only the equation of the cutting surface on the left side of the axis $Y_{1}$ is given here. The equation of the cutting surface on the right side can be obtained by symmetry transform.

\section{TOOTH SURFACE EQUATIONS OF THE MACHINED GEAR}

The position relationship of the coordinate systems has been analysed above. According to the principle of conjugate motion between the cutting surface and the gear tooth surface, vector $\mathrm{r}^{(1)}$ in cutter coordinate system $\sigma^{(1)}$ can be transformed into the gear coordinate system $\sigma^{(2)}$, and the tooth surface equation of the machined gear is obtained as follows:

$$
\left\{\begin{array}{l}
\mathbf{r}^{(2)}=\mathbf{M}_{21} \mathbf{r}^{(1)}+\mathbf{r}_{01}^{(2)} \\
\mathbf{r}_{01}^{(2)}=\mathbf{M}_{20} \mathbf{r}_{01}+\mathbf{r}_{0}^{(2)} \\
\mathbf{n}^{(1)} \cdot \mathbf{V}^{(12)}=0
\end{array}\right.
$$

where $\mathbf{M}_{20}$ is the transformation matrix from coordinate system $\sigma$ to coordinate system $\sigma^{(2)}, \mathrm{r}_{01}^{(2)}$ is the vector of the origin $O_{1}$ of coordinate system $\sigma^{(1)}$ in coordinate system $\sigma^{(2)}$, $\mathbf{r}_{0}^{(2)}$ is the vector of the origin $O$ of coordinate system $\sigma$ in coordinate system $\sigma^{(2)}$.

The tooth surface equation of a gear in the Cartesian coordinate system can be developed as shown in Eq. (13) by substituting the cutting surface equation and meshing equation mentioned above into Eq. (12).

$$
\left\{\begin{array}{l}
x_{2}=x_{1} \cos \varphi_{2}-y_{1} \sin \varphi_{2}+r_{2} \varphi_{2} \cos \varphi_{2}-r_{2} \sin \varphi_{2} \\
y_{2}=x_{1} \sin \varphi_{2}+y_{1} \cos \varphi_{2}+r_{2} \varphi_{2} \cos \varphi_{2}+r_{2} \sin \varphi_{2} \\
z_{2}=z_{1}-L_{2} \\
\mathbf{n}^{(1)} \cdot \mathbf{V}^{(12)}=0
\end{array}\right.
$$


where $z_{2} \in\left[0, b_{c}\right], b_{c}$ is the width of the gear tooth, $L_{2}$ is an independent variable. The fourth term in Eq. (13) is the meshing equation. It is different when machining different parts of a gear.

The involute surface is cut by the section $A D$ of the rack cutter. The corresponding meshing equation is as follows:

$$
-y_{1} \cos \alpha+\left(x_{1}+r_{2} \varphi_{2}\right) \sin \alpha=0
$$

The root fillet surface is cut by section $D E$ of the rack cutter. The corresponding meshing equation is as follows:

$$
y_{1} \cos \xi-\left(x_{1}+r_{2} \varphi_{2}\right) \sin \xi=0
$$

The tooth root surface is cut by section $E F$ of the rack cutter. The corresponding meshing equation is as follows:

$$
x_{1}+r_{2} \varphi_{2}=0
$$

According to meshing equations and cutting surface equations in the above, $\varphi_{2}$ can be represented by $\mu_{1}$. So, there are two independent variables $\mu_{1}$ and $L_{2}$, which correspond to the double-degree freedom of meshing principle.

When machining the gear with modifications, simply move the rack teeth along axis $\mathrm{Y}_{1}$ by $x m$ ( $x$ is the modification coefficient and $m$ is the module of the rack cutter tooth), and recalculate the corresponding parameter and the tooth surface equation.

\section{ANALYSIS OF MESHING PROPERTIES FOR THE SPUR GEAR PAIR}

\subsection{Finite element model of spur gear pair}

Based on the tooth surface equation of the gear deduced above, the parametric modelling program for establishing the finite element (FE) model of the machined gear is developed on the ANSYS software platform by using APDL second development language. The main flow for establishing the finite element model of the spur gear pair is shown in Fig. 3.

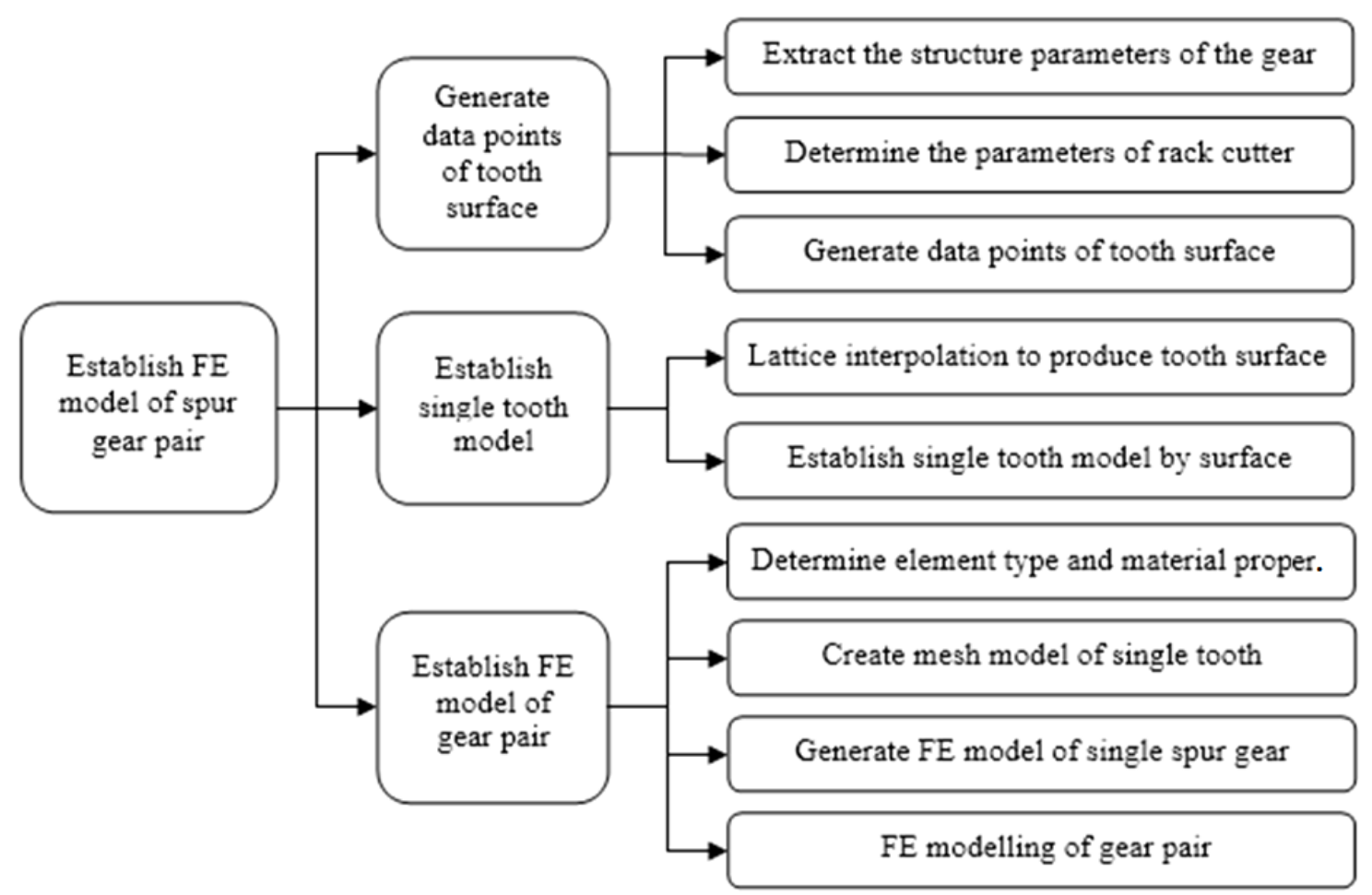

Figure 3: Technical flow of establishing the FE model of gear pair. 
Firstly, a set of parameters of $\mu_{1}$ and $L_{2}$ are respectively given within the range of their effective values, and according to the tooth surface equation deduced above, the data points on the tooth surface of a single tooth are calculated as shown in Fig. 4. The data points of the other teeth can be obtained by rotating replication.

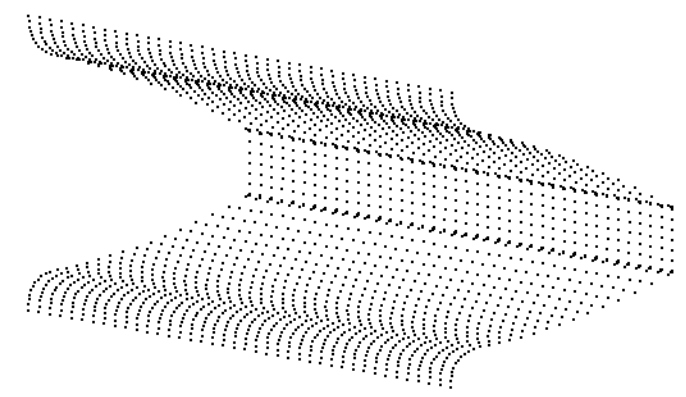

Figure 4: Data points of single tooth surface.

Based on the interpolation principle of the cubic B-spline surface, the tooth surface of the machined gear can be interpolated by the data points calculated above, and then the solid model of the gear can be established by using the general modelling function of CAD software. In order to improve the accuracy of analysis results, the hexahedral element solid185 is used to create the FE mesh model.

Since the actual meshing process of the teeth is periodic and considering that there are at most two pairs of teeth engaged at the same time, a simplified FE model of gear pair with five pairs of teeth is used in this paper to improve the efficiency. The structure of the hub and shaft hole, which has little influence on the strength of the gear tooth, is also simplified. Fig. 5 shows the FE mesh model of the spur gear pair.

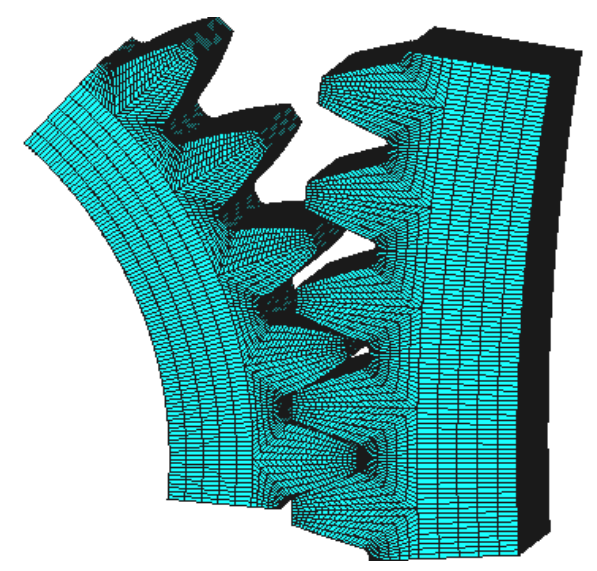

Figure 5: FE mesh model of the spur gear pair.

Because the damage of the tooth mainly occurs in the tooth surface and tooth root, fine mesh is necessary for these two parts of the gear to ensure the calculation accuracy. The hub has little influence on the strength of the gear teeth, and the coarse mesh can be used.

\subsection{Transient meshing analysis of the spur gear pair}

After the simplified FE model of spur gear pair is established, the contact pairs are created between conjugate tooth surfaces. The inner holes of the two gears are respectively stiffened, and the rotation of the gear is realized through the corresponding central node.

The inner surfaces of the shaft holes of the driving and driven gears are respectively rigidized and controlled by the control nodes. Then, the angular velocity is applied to the driving gear, and the resistance torque is applied to the driven gear. Finally, the analysis type, 
the number of load step, solution time and other options are set for transient meshing analysis [15].

The main forms of gear tooth failure are tooth surface pitting and tooth breakage. Therefore, the tooth contact stress and bending stress are the main elements in gear strength analysis. Among them, the crack caused by bending stress has an important impact on the bending life [16]. The simplified FE model of the gear pair is used to carry out the transient meshing analysis, in which the third pair of teeth will undergo a complete meshing process. The distribution and varieties of the contact stress and bending stress during the meshing process of the third pair of teeth are analysed.

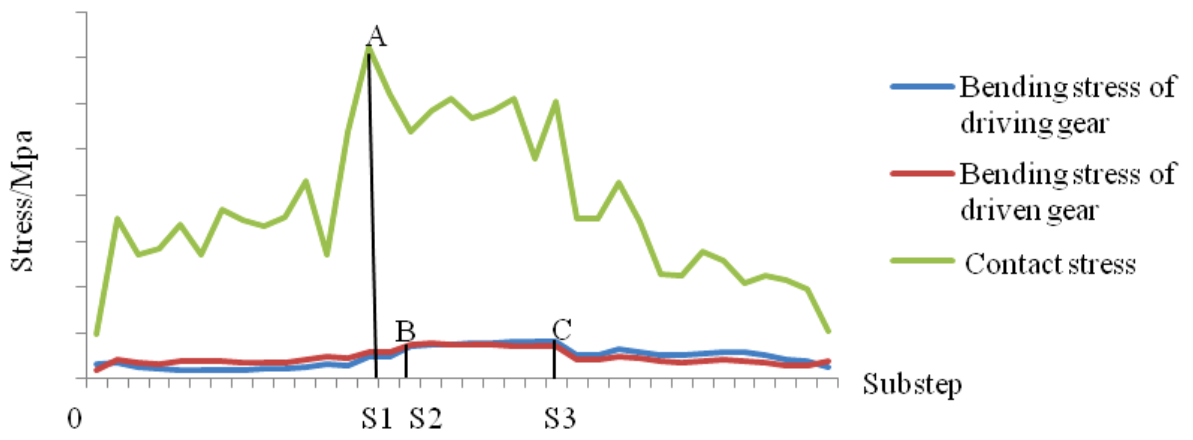

Figure 6: Stress-substep curve of the third pair of teeth.

As shown in Fig. 6, the contact stress reaches the maximum at substep S1, the bending stress of the driven gear reaches the maximum at substep $S 2$, and the bending stress of the driving gear reaches the maximum at substep S3. It is very important to know the maximum stress value for strength checking. The corresponding substep of maximum stress can help to determine the worst position of the engagement, and then determine the exact locations where the teeth are easily damaged.

\section{SIMULATION EXAMPLE AND RESULTS COMPARISON}

The difference between the machining principle model and the traditional model is mainly in the root fillet surface. The traditional method uses a cylindrical surface with an empirical radius instead of a root fillet surface formed by the cutting tool. The proposed method simulates the cutting process to produce a precise tooth root fillet surface. Aiming at the two modelling methods, this paper has conducted much simulation analysis. In order to effectively reflect the superiority of this method, one of them is selected to illustrate.

Table I: Parameters of spur gear and working condition.

\begin{tabular}{|l|c|c|c|c|c|c|c|}
\hline Parameters & $\begin{array}{c}\text { Number } \\
\text { of teeth } \\
z\end{array}$ & $\begin{array}{c}\text { Module } \\
m\end{array}$ & $\begin{array}{c}\text { Press } \\
\text { angle } \\
\alpha\left(^{\circ}\right)\end{array}$ & $\begin{array}{c}\text { Width of } \\
\text { tooth } b(\mathrm{~mm})\end{array}$ & $\begin{array}{c}\text { Modification } \\
\text { coefficient } x\end{array}$ & $\begin{array}{c}\text { Driving } \\
\text { rotation } \\
\text { speed } n_{1} \\
(\mathrm{r} / \mathrm{min})\end{array}$ & $\begin{array}{c}\text { Input } \\
\text { power } p \\
(\mathrm{~kW})\end{array}$ \\
\hline Driving gear & 34 & 2 & 20 & 75 & 0.502 & \multirow{2}{*}{960} & \multirow{2}{*}{10} \\
\hline Driven gear & 109 & 2 & 20 & 68 & 0.503 & \\
\hline
\end{tabular}

The gear modelling and simulation analysis process have already been given, and the Btype rack cutter can be determined according to the standard JIS B1701-1:2012 [17].

In the traditional method of modelling and analysis, root fillet surfaces of the gear are replaced by cylindrical surfaces with a radius between $0.2 m$ to $0.5 m$ ( $m$ is the module). In order to comprehensively compare the difference between the traditional model and the machining model, the corresponding program based on APDL was compiled, and fillet radii 
of $0.28 \mathrm{~m}, 0.38 \mathrm{~m}$ and $0.45 \mathrm{~m}$ were selected for modelling and analysis. According to the above method, the FE model of each gear pair was created by using the given parameters, and the transient meshing simulation was performed. Then, the maximum contact stress and bending stress of the third tooth pair in each load step were obtained and corresponding time-history curves were drawn.

\subsection{Comparison of bending stress}

The bending stress of the third tooth pair during the meshing process for four kinds of gear pair models with different root fillet surface are show in Figs. 7 and 8.

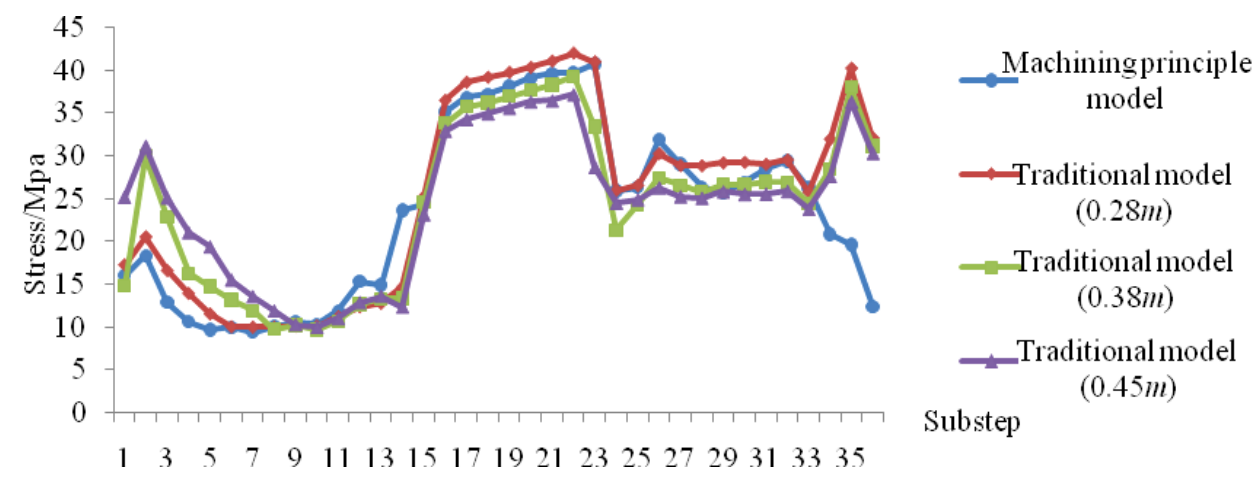

Figure 7: Bending stress of the driving gear.

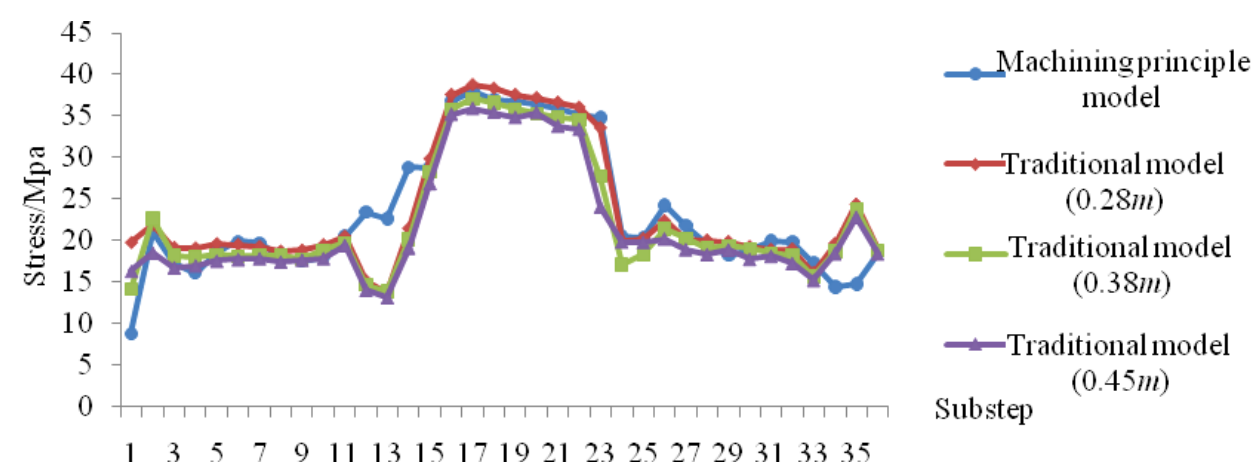

Figure 8: Bending stress of the driven gear.

Figs. 7 and 8 show the bending stress of the gear tooth decreases with the increase in the radius of the root fillet surface. In traditional modelling method, due to the lack of a uniform standard, different technicians chose different root fillet radii, which lead to different calculation results of the bending strength, making it very difficult to obtain accurate results. For the gear model established by the method proposed in this study, as the tooth surface equation is derived by the machining principle, the model is unique and is exactly the same as the actual gear, and thus can be used to accurately calculate the bending stress of the gear tooth.

Furthermore, at the moments when the third pair of teeth begins to engage or withdraw form engagement, stress concentration appeared in four sets of gear models. But the value of the stress concentration for the machining principle model is lower. Therefore, the influence of stress concentration is well controlled. The stress value and change trend of the gear model with the fillet radius of $0.28 \mathrm{~m}$ are in good agreement with the machining principle model.

As shown in Fig. 9, if the fillet radius is $0.38 \mathrm{~m}$ or $0.45 \mathrm{~m}$, the involute curve in the tooth root is truncated, which leads to the advanced engagement with the conjugate tooth tip and resulting in a large stress concentration. The analysis found that when the fillet radius is $0.28 \mathrm{~m}$, the root fillet surfaces generated by the two modelling methods are very similar. 
However, in the actual design process, it is difficult to select the most appropriate root fillet radius.

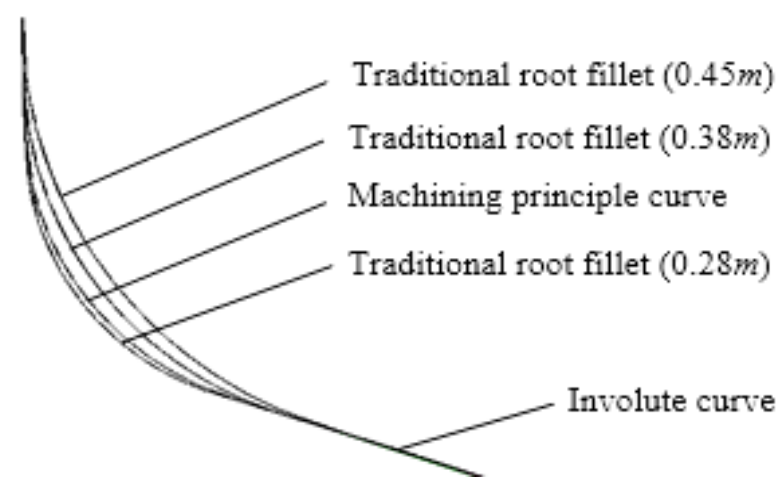

Figure 9: Shape comparison of four sets of root fillet curves.

In the process of exiting engagement, the gear pair generated by the traditional modelling method has obvious stress concentration. However, the stress of the gear pair generated by machining principle is very stable, being more in accord with the actual situation of gear meshing. As shown from substeps 11 to 13 in Fig. 8, the bending stress of the gear generated by the traditional method dropped first and then raised in the alternating process of doubletooth engagement into the single-tooth engagement, which is due to the stress concentration caused by the meshing impact of the last pair of meshing teeth.

\subsection{Comparison of contact stress}

The contact stresses of the third pair of teeth during the meshing process for four kinds of gear pair models are show in Fig. 10. As can be seen from the figure, whether the gear model is created by the traditional method or by the machining principle, the contact stress and its variation trend are different.

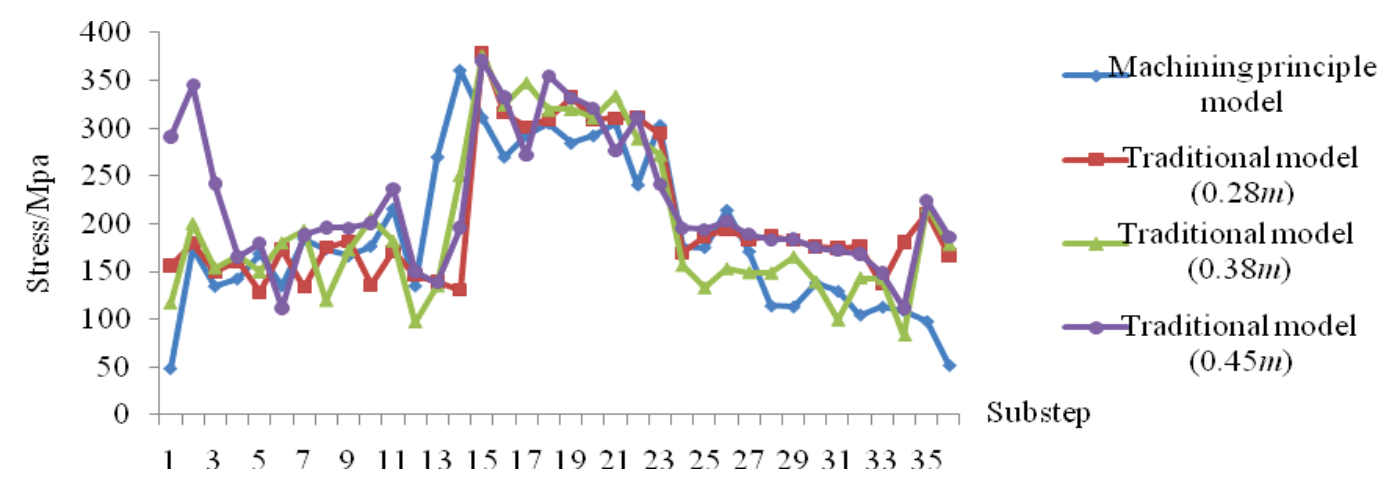

Figure10: Tooth contact stress of four sets of gear models.

According to the theoretical basis [18] of gear strength calculation, the contact stress of a gear tooth reaches the maximum at the highest position of the driven gear with single tooth engagement. For the gear pair in the simulation example, when the contact stress of the gear tooth reaches the maximum, the theoretical rotation angle [19] of the driven gear relative to the initial position is $5.499881^{\circ}$. As the contact stress of the gear model generated by the machining principle reaches the maximum, the rotation angle of the driven gear relative to the initial position is $5.546351^{\circ}$, which is very close to the theoretical value. However, when the contact stresses of the other three gear models generated by the traditional modelling method reach the maximum, the corresponding meshing positions are not at the highest points of the driven gears with single tooth engagement. The root fillet radius determines the location of 
the maximum contact stress. This shows that the accuracy of the root fillet surface has a great influence on the contact stress of the gear tooth.

In addition, the bending stress of the driven gear established by the machining principle reaches the maximum as the gear pair meshes at the highest position of the driven gear with single engagement. The rotation angle of the driven gear relative to the initial position of the gear is $5.986538^{\circ}$, which is also very close to the theoretical value $5.499881^{\circ}$.

Combined with the results of the above analysis, the meshing positions in the driven gear where the contact stress and bending stress respectively reach the maximum are very close. Both of them are located at the highest point of the driven gear with single tooth engagement. This position is consistent with the theoretical analysis.

\section{CONCLUSION}

In this paper, the accurate modelling and strength simulation analysis technology of spur gears are studied and realized. The relevant methods are verified by simulation example and comparative analysis. Some conclusions can be drawn as follows.

(1) The tooth root fillet surface shape of the gear model established by the machining principle is the same shape as the actual gear. The simulation analysis based on this model accords with the theory of gear meshing, and the example shows that the modelling method is feasible and accurate.

(2) The root fillet surface is a complex surface, depending on the corner radius of the cutter. The traditional modelling method with fixed root fillet radius is not scientific.

(3) There are some errors in the values and positions of the maximum bending stress and maximum contact stress obtained by traditional modelling and simulation method. The shape accuracy of the tooth root fillet surface has a great influence on tooth contact stress and tooth root bending stress.

(4) There are two most vulnerable meshing positions in the meshing process. One is the highest point of the driving gear with single tooth engagement, where the bending stress of the driving gear reaches the maximum. The other is the highest point of the driven gear with single tooth engagement, where both the bending stress of the driven gear and the tooth contact stress of the gear pair reach the maximum.

Although the modelling method proposed in this paper improves the accuracy of the gear model, there are also some minute errors in the simulation analysis result because the complete gear pair model is not used.

\section{ACKNOWLEDGEMENT}

This work was supported by the National Natural Science Foundation of China (Grant No. 51375282 $\&$ 51674155), the Special Funds for Cultivation of Taishan Scholars, the Shandong Provincial Natural Science Foundation of China (Grant No. ZR2015EM017) and the Science and Technology Development Program of Shandong Province (Grant No. 2014GGX103043).

\section{REFERENCES}

[1] Pedrero, J. I.; Pleguezuelos, M.; Muñoz, M. (2011). Contact stress calculation of undercut spur and helical gear teeth, Mechanism and Machine Theory, Vol. 46, No. 11, 1633-1646, doi:10.1016/j.mechmachtheory.2011.06.015

[2] Tang, J.-Y.; Liu, Y.-P. (2013). Loaded multi-tooth contact analysis and calculation for contact stress of face-gear drive with spur involute pinion, Journal of Central South University, Vol. 20, No. 2, 354-362, doi:10.1007/s11771-013-1495-x 
[3] Hwang, S.-C.; Lee, J.-H.; Lee, D.-H.; Han, S.-H.; Lee, K.-H. (2013). Contact stress analysis for a pair of mating gears, Mathematical and Computer Modelling, Vol. 57, No. 1-2, 40-49, doi:10.1016/j.mcm.2011.06.055

[4] Forte, P.; Paoli, A.; Razionale, A. V. (2015). A CAE approach for the stress analysis of gear models by 3D digital photoelasticity, International Journal on Interactive Design and Manufacturing, Vol. 9, No. 1, 31-43, doi:10.1007/s12008-013-0201-4

[5] Lias, M. R.; Awang, M.; Rao, T. V. V. L. N.; Fadhil, M. (2014). Evaluation of spur gear pair on tooth root bending stress in yawing misalignment contact condition, Advanced Materials Research, Vol. 980, 97-101, doi:10.4028/www.scientific.net/AMR.980.97

[6] Yusuf, O. T.; Zhao, G.; Wang, W.; Onuh, S. O. (2015). Simulation based on trivariate nurbs and isogeometric analysis of a spur gear, Strength of Materials, Vol. 47, No. 1, 19-28, doi: $10.1007 / \mathrm{s} 11223-015-9623-5$

[7] Kanber, B. (2006). Analysis of spur gears by coupling finite and boundary element methods, Mechanics Based Design of Structures and Machines, Vol. 34, No. 3, 307-324, doi: 10.1080/15397730600889498

[8] Karpat, F.; Ekwaro-Osire, S.; Cavdar, K.; Babalik, F. C. (2008). Dynamic analysis of involute spur gears with asymmetric teeth, International Journal of Mechanical Sciences, Vol. 50, No. 12, 1598-1610, doi:10.1016/j.ijmecsci.2008.10.004

[9] Ma, H.; Song, R.; Pang, X.; Wen, B. C. (2014). Time-varying mesh stiffness calculation of cracked spur gears, Engineering Failure Analysis, Vol. 44, 179-194, doi:10.1016/ j.engfailanal.2014.05.018

[10] Xu, S.; Zhang, Y. (2012). The finite element modeling and analysis of involute spur gear, Advanced Materials Research, Vols. 516-517, 673-677, doi:10.4028/www.scientific.net/ AMR.516-517.673

[11] Pawar, P. B.; Utpat, A. A. (2015). Analysis of composite material spur gear under static loading condition, Materials Today: Proceedings, Vol. 2, No. 4-5, 2968-2974, doi:10.1016/ j.matpr.2015.07.278

[12] Fetvaci, C.; Imrak, E. (2008). Mathematical model of a spur gear with asymmetric involute teeth and its cutting simulation, Mechanics Based Design of Structures and Machines, Vol. 36, No. 1, 34-46, doi:10.1080/15397730701735731

[13] Litvin, F. L.; Fuentes, A. (2004). Gear Geometry and Applied Theory, $2^{\text {nd }}$ ed., Cambridge University Press, Cambridge

[14] Zheng, G. L.; Zhang, L.; Zhuan, X. T.; Shang, X. D. (2015). A measuring method for threedimensional turbulent velocities based on vector decomposition and synthesis, International Journal of Heat and Technology, Vol. 33, No. 4, 51-60, doi:10.18280/ijht.330407

[15] Zeng, Q. L.; Jiang, S. B.; Wan, L. R.; Li, X. Y. (2015). Finite element modeling and analysis of planetary gear transmission based on transient meshing properties, International Journal of Modeling, Simulation, and Scientific Computing, Vol. 6, No. 3, Paper ID 1550035, 20 pages, doi:10.1142/S179396231550035X

[16] Wang, X. L.; He, L. L. (2016). Study on the fatigue crack growth of 3D surface of the curved steel plate, Chemical Engineering Transactions, Vol. 55, 331-336, doi:10.3303/CET1655056

[17] JIS B1701-1 (2012). Cylindrical gears for general and heavy engineering - Part 1: Standard basic rack tooth profile, Japanese Standards Association, Tokyo

[18] Childs, P. R. N. (2004). Mechanical Design, $2^{\text {nd }}$ ed., Elsevier Butterworth-Heinemann, Oxford

[19] Li, X. Y.; Li, S. S.; Li, C. C. (2011). Transient dynamics simulation of helical gear pair based on ANSYS, Advanced Materials Research, Vol. 230-232, 578-581, doi:10.4028/www.scientific.net/ AMR.230-232.578 